\title{
Optimization of Process Variables in the Biodiesel Production from Lophira lanceolata Seed Oil
}

\author{
M. Z. Kyari, S. M. Danggoggo, B. B. Usman and *A. B. Muhammad \\ Department of Pure and Applied Chemistry Usmanu Danfodiyo University, Sokoto, Nigeria \\ [ ${ }^{\star}$ Corresponding Author: E-mail: muhammad.aminu@udusok.edu.ng; I: +2348030537838]
}

\begin{abstract}
Box-Behnken response surface methodology was employed to optimize the process variables in alkalinecatalysed transesterification of Lophira lanceolata seed oil into biodiesel following initial acid-catalysed esterification. The model equation obtained from regression analysis adequately expressed the relationship between the biodiesel yield and the process variables with $\mathrm{R}^{2}$ of $96.05 \%$. The optimization result suggested the best combination of the process variables for optimum biodiesel yield of $85.0 \%$ are: reaction temperature $\left(50^{\circ} \mathrm{C}\right)$; reaction time $(120 \mathrm{~min})$; amount of methanol $(6 \mathrm{~cm} / \mathrm{g}$ oil) and catalyst concentration $\left(0.30 \mathrm{~mol}^{-} / \mathrm{dm}^{-3}\right)$. Validation yield of $83 \%$ compares favorably with the predicted value, showing model reliability in describing the transesterification process. Results of GC-MS analysis of the biodiesel revealed it mainly consists of methyl esters of octadecenoic acid $(69.5 \%)$, palmitic acid $(9.4 \%)$ and hexacosanoic acid (5.6\%). The biodiesel was very fluid $2.70 \pm 0.12 \mathrm{~mm} / \mathrm{s}^{2}$ with most of it fuel properties in conformity with ASTM standards making it suitable as fuel for diesel engines.
\end{abstract}

Keywords: Optimization, Lophira lanceolata, transesterification, Biodiesel, Behnken design.

\section{INTRODUCTION}

Biodiesel is a mixture of monoalkyl esters derived from vegetable oils or animal fats. It has properties that are similar to petrodiesel and can thus be used in diesel engines with no engine modification (Atadashi et al., 2010). It is renewable, biodegradable, non-toxic and produces much less harmful emissions than conventional petrodiesel (Antolin et al., 2002; Issariyakul et al., 2008). However, it has slightly lower calorific value than petrodiesel and cost about 1.5 to 3 times higher largely due to high cost of raw materials (Abbaszaadeh et al., 2012).

Biodiesel is produced from wide range of feedstock (Fan et al., 2010; Gui et al., 2008; Karmakar et al., 2010) although, for both economics and food security reasons (Wiebe et al., 2008), there is more emphasis on non-edible oils (Gui et al., 2008; Haas, 2005). Consequently, spent or used oils are gaining attention as low cost raw materials for biodiesel production (Enweremadu and Mbarawa, 2009; Leung and Guo, 2006; Meneghetti et al., 2007; Moser, 2008). However, the most promising feedstocks are non-edible oils, such as $L$. siceraria (Muhammad et al., 2015), $H$. brasiliensi (Muhammad et al., 2016), and J. curcas (Koh and Ghazi, 2011; Yang et al., 2012).

Nevertheless, irrespective of the source, biodiesel preparation is influenced by a number of factors including reaction temperature, reaction time, methanol/oil ratio and concentration of the catalyst used (Gondra, 2010; Muhammad et al., 2016). The optimal levels of these factors are also a function of the nature of oil being esterified (Gondra, 2010; Nkafamiya et al., 2010; Singh and Singh, 2009). Hence, transesterification of any given oil needs to be optimized to determine the best conditions for optimal yield. Thus, in this work we used Box-Behnken response surface design to optimize the process variables for conversion of L. lanceolata seed oil into biodiesel.

L. lanceolata is a small to medium-sized deciduous ironwood tree (up to $16 \mathrm{~m}$ tall and $70 \mathrm{~cm}$ diameter) with a narrow crown and ascending branches. It is found in savannah in the wild on medium heavy to sandy or gravelly soil. 


\section{MATERIALS AND METHODS}

\section{Chemicals, solvents and oilseeds}

All chemicals and solvents used in this work were of analytical grade manufactured by British Drug House (BDH). These included methanol $(99.5 \%)$, sodium hydroxide $(95 \%)$, sulphuric acid $(98 \%)$ and petroleum ether. The chemicals and solvents were used as procured without further purification.

Seeds of $L$. lanceolata was obtained from the premises of Bauchi Campus of Abubakar Tafawa Balewa University, Bauchi, Nigeria. They were manually separated from the kernels, dried and grounded into powder. Oils were extracted from the grounded seeds by Soxhlet extraction for 6 hours using petroleum ether as solvent (Muhammad et al., 2015).

\section{Acid-catalysed esterification}

A solution consisting of methanol $(2.25 \mathrm{~g})$ and sulphuric acid $(0.05 \mathrm{~g})$ was added to the oil for every $1 \mathrm{~g}$ of the free fatty acid. The mixture was stirred at $60^{\circ} \mathrm{C}$ for an hour and allowed to settle for the oil and methanol-water layers to separate. The methanol-water layer was discarded and the bottom oil layer was recovered and analysed for its free fatty acids content. The esterified oil was used in the subsequent experiments.

\section{Design of experiment}

Response surface (Box-Behnken) experimental design was used to design the experiments on MINITAB 16 statistical software platform. The aim was to model optimization of transesterification conditions of the oil using methanolic sodium hydroxide as catalyst (Fan et al., 2011; Muhammad et al., 2015; Muhammad et al., 2016). Thus, four independent variables reaction time, reaction temperature, amount of methanol and catalyst concentration -were investigated and optimized. Table 1 shows the lower and upper levels of the factors employed in the design based on literature survey (Prommuak et al., 2012; Silva et al., 2011) Each trial was replicated and all the runs were completely randomized to obtain a total of 58 runs (see Table 2 for the design matrix). The amount of oil was kept constant at $5 \mathrm{~g}$ for each run.

\section{Description of the experimental trial}

In each trial (Table 2), esterified oil $(5.0 \mathrm{~g})$ was placed in a round-bottomed flask followed by the addition of appropriate volume $(20,30$ or 40 $\mathrm{cm}^{3}$ ) of freshly prepared methanolic sodium hydroxide solution of concentration $(0.30,0.475$ or $0.65 \mathrm{M})$. The mixture was then refluxed at a constant temperature $\left(40,50\right.$ or $\left.60^{\circ} \mathrm{C}\right)$ for a specific period of time $(40,80$ or 120 minutes). Thereafter, the flask was allowed to cool and its contents settled. The mixture was then filtered, and the filtrate was transferred into a separating funnel, and then water $\left(10 \mathrm{~cm}^{3}\right)$ were added to facilitate separation into aqueous and organic layers. The aqueous, glycerol-rich layer was ran off while the organic, biodiesel-rich layer was collected, washed with distilled water and dried over anhydrous sodium sulphate, and finally dried at $60^{\circ} \mathrm{C}$ to obtain the biodiesel. The percentage of the biodiesel obtained relative to the $5.0 \mathrm{~g}$ of the oil was calculated from Equation1 (Muhammad et al., 2015; Muhammad et al., 2016).

$$
\begin{aligned}
& \text { Biodiesel yield, } y(\%) \\
& =\frac{\text { wt of biodiesel obtained }(\mathrm{g}) \times 100}{5 \mathrm{~g} \text { of the oil used }} \\
& -----------(1)
\end{aligned}
$$

Table 1: Independent variables and their levels as used in the Box-Behnken experimental design

\begin{tabular}{llllll}
\hline SN & Independent variable & Code & Lower level & Mid-level & Upper level \\
\hline 1 & Temperature $\left({ }^{\circ} \mathrm{C}\right)$ & $d$ & 40 & 50 & 60 \\
2 & Time $($ minute) & $t$ & 40 & 80 & 120 \\
3 & Methanol $\left(\mathrm{cm}^{3}\right)$ & $m$ & 20 & 30 & 40 \\
4 & Catalyst $(\mathrm{M})$ & $c$ & 0.300 & 0.475 & 0.650 \\
\hline
\end{tabular}


Molecular assay of the biodiesel

A sample of the biodiesel was analysed for its methyl esters composition using a gas chromatography (Agilent 6890N) coupled to mass spectrometer (Agilent 5973 MSD) system equipped with a split injection system. $1 \mu$ of the sample was injected into the injector (at $250^{\circ} \mathrm{C}$ ). The column was a DB-1ms capillary column $(30 \mathrm{~m} \times 320 \mu \mathrm{m}$ (id), with a film thickness of 1 $\mu \mathrm{m})$. Helium $\left(1.2 \mathrm{~cm}^{3} / \mathrm{min}\right)$ was the carrier gas. The oven temperature was programmed from $60^{\circ} \mathrm{C}$ (held for 5 minutes) to $250^{\circ} \mathrm{C}$ (held for 5 minutes) at a rate of $3^{\circ} \mathrm{C} / \mathrm{min}$. The chromatogram and mass spectrum of the eluted compounds were recorded on a computer using Chemstation software.

Table 2. The design matrix and results of biodiesel yield from the experimental trials conducted.

\begin{tabular}{|c|c|c|c|c|c|c|}
\hline Trial & $\begin{array}{l}\text { Temp. } \\
\left(0^{\circ} \mathrm{C}\right)\end{array}$ & $\begin{array}{l}\text { Time } \\
\text { (min) }\end{array}$ & $\begin{array}{l}\text { Catalyst } \\
\text { (M) }\end{array}$ & $\begin{array}{l}\text { Methanol } \\
\left(\mathrm{cm}^{3}\right)\end{array}$ & $\begin{array}{l}\text { Yield, Actual } \\
\text { value (\%) }\end{array}$ & $\begin{array}{l}\text { Yield, Predicted } \\
\text { value }(\%)\end{array}$ \\
\hline 1 & 40 & 40 & 0.65 & 30 & 47 & 48.27 \\
\hline 2 & 60 & 40 & 0.65 & 30 & 63 & 58.55 \\
\hline 3 & 40 & 120 & 0.65 & 30 & 72 & 70.78 \\
\hline 4 & 60 & 120 & 0.65 & 30 & 81 & 81.06 \\
\hline 5 & 50 & 80 & 0.30 & 20 & 73 & 74.93 \\
\hline 6 & 50 & 80 & 0.47 & 20 & 54 & 54.55 \\
\hline 7 & 50 & 80 & 0.30 & 40 & 76 & 72.88 \\
\hline 8 & 50 & 80 & 0.47 & 40 & 58 & 56.53 \\
\hline 9 & 40 & 80 & 0.65 & 20 & 58 & 58.83 \\
\hline 10 & 60 & 80 & 0.65 & 20 & 70 & 70.65 \\
\hline 11 & 40 & 80 & 0.65 & 40 & 61 & 59.17 \\
\hline 12 & 60 & 80 & 0.65 & 40 & 69 & 70.24 \\
\hline 13 & 50 & 40 & 0.30 & 30 & 56 & 55.95 \\
\hline 14 & 50 & 120 & 0.30 & 30 & 85 & 85.45 \\
\hline 15 & 50 & 40 & 0.47 & 30 & 48 & 50.88 \\
\hline 16 & 50 & 120 & 0.47 & 30 & 70 & 66.38 \\
\hline 17 & 40 & 80 & 0.30 & 30 & 65 & 65.19 \\
\hline 18 & 60 & 80 & 0.30 & 30 & 75 & 76.21 \\
\hline 19 & 40 & 80 & 0.47 & 30 & 53 & 53.87 \\
\hline 20 & 60 & 80 & 0.47 & 30 & 62 & 63.40 \\
\hline 21 & 50 & 40 & 0.65 & 20 & 50 & 47.23 \\
\hline 22 & 50 & 120 & 0.65 & 20 & 81 & 82.26 \\
\hline 23 & 50 & 40 & 0.65 & 40 & 50 & 50.23 \\
\hline 24 & 50 & 120 & 0.65 & 40 & 79 & 79.18 \\
\hline 25 & 50 & 80 & 0.65 & 30 & 64 & 64.67 \\
\hline 26 & 50 & 80 & 0.65 & 30 & 64 & 64.67 \\
\hline 27 & 50 & 80 & 0.65 & 30 & 64 & 64.67 \\
\hline 28 & 50 & 80 & 0.65 & 30 & 64 & 64.67 \\
\hline 29 & 50 & 80 & 0.65 & 30 & 64 & 64.67 \\
\hline 30 & 40 & 40 & 0.65 & 30 & 61 & 57.32 \\
\hline 31 & 60 & 40 & 0.65 & 30 & 63 & 64.43 \\
\hline 32 & 40 & 120 & 0.65 & 30 & 74 & 73.83 \\
\hline 33 & 60 & 120 & 0.65 & 30 & 83 & 80.94 \\
\hline 34 & 50 & 80 & 0.30 & 20 & 73 & 73.88 \\
\hline 35 & 50 & 80 & 0.47 & 20 & 60 & 58.50 \\
\hline 36 & 50 & 80 & 0.30 & 40 & 78 & 73.29 \\
\hline 37 & 50 & 80 & 0.47 & 40 & 61 & 61.94 \\
\hline 38 & 40 & 80 & 0.65 & 20 & 60 & 61.86 \\
\hline 39 & 60 & 80 & 0.65 & 20 & 70 & 70.51 \\
\hline 40 & 40 & 80 & 0.65 & 40 & 62 & 63.66 \\
\hline
\end{tabular}




\begin{tabular}{lllllll}
\hline 41 & 60 & 80 & 0.65 & 40 & 70 & 71.57 \\
\multicolumn{2}{l}{ Table 2 Continued } & & & & & \\
42 & 50 & 40 & 0.30 & 30 & 60 & 60.91 \\
43 & 50 & 120 & 0.30 & 30 & 85 & 84.42 \\
43 & 60 & 80 & 0.30 & 30 & 67 & 60.84 \\
44 & 50 & 40 & 0.47 & 30 & 71 & 70.35 \\
45 & 50 & 120 & 0.47 & 30 & 68 & 68.73 \\
46 & 40 & 80 & 0.30 & 40 & 77 & 76.59 \\
48 & 40 & 80 & 0.47 & 30 & 60 & 62.41 \\
49 & 60 & 80 & 0.47 & 30 & 67 & 68.77 \\
50 & 50 & 40 & 0.65 & 20 & 51 & 51.67 \\
51 & 50 & 120 & 0.65 & 20 & 84 & 80.70 \\
52 & 50 & 40 & 0.65 & 30 & 55 & 56.14 \\
53 & 50 & 120 & 0.65 & 40 & 78 & 79.09 \\
54 & 50 & 80 & 0.65 & 30 & 68 & 69.13 \\
55 & 50 & 80 & 0.65 & 30 & 68 & 69.13 \\
56 & 50 & 80 & 0.65 & 30 & 68 & 69.13 \\
57 & 50 & 80 & 0.65 & 30 & 68 & 69.13 \\
58 & 50 & 80 & 0.65 & 30 & 68 & 69.13 \\
\hline
\end{tabular}

Determination of the physicochemical properties

Some physicochemical properties of the biodiesel were determined according to standard procedures: density (ASTM D 5002), kinematic viscosity (ASTM D445), flash point (ASTM D 93), cloud point (ASTM D 2500), pour point (ASTM D 97), acid value (ASTM D 664), ash content (ASTM D 874), and sulphur (ASTM D2622) were determined in triplicates, and the results are presented as the mean \pm standard deviation.

Cetane number $(C N)$ of the biodiesel was calculated from equation 2 using the saponification value (SV) and iodine value (IV)of the biodiesel (Krisnangkura, 1986), and high heating value $(\mathrm{HHV})$ was estimated from equation 3 using viscosity (VS) (Demirbas, 2008)

$C N=46.3+\frac{5458}{S V}-0.225 I V$

$H H V=0.4625 V S+39.450$

\section{Data analysis}

The response, $y$ (i.e. biodiesel yield) was fitted with a full quadratic polynomial regression model (eq.4) in order to correlate the yield to the operating variables.

$$
\begin{aligned}
y=\beta^{0}+\sum_{i=1}^{4} \beta_{i} x_{i} & +\sum_{i=1}^{4} \beta_{i i} x_{i}^{2} \\
& +\sum_{i=1}^{4} \sum_{j=i+1}^{4} \beta_{i j} x_{i} \quad x_{j}
\end{aligned}
$$

Where $\beta_{o} \beta_{i}, \beta_{i i}, \beta_{i j}$ are intercept, linear, quadratic and interaction coefficients respectively, and $x_{i}$ and $x_{j}$ are the independent variables, respectively. The quality of the model fit was evaluated using the coefficient of determination $\left(R^{2}\right)$ and effect of terms was evaluated using ANOVA at $a=0.05$. Surface plots were developed using the fitted quadratic polynomial equation obtained from the regression analysis while holding two of the independent variables at constant levels. MINITAB 16 statistical software was used for the data as well as optimization of the results.

\section{RESULTS AND DISCUSSION}

The oil yield of the seed was found to be 37.00 $\pm 0.33 \%$ with significantly high free fatty acid content of $4.56 \pm 0.22 \mathrm{mg} \mathrm{NaOH} / \mathrm{g}$ oil which necessitated acid-catalysed esterification of the oil before alkaline-catalysed transesterification to avoid soap formation and consequent low yields of the biodiesel (Demirbas, 2003). Following the esterification, free fatty acid determination revealed that the oil had $<0.50$ $\mathrm{mg} \mathrm{KOH} / \mathrm{g}$ oil of free fatty acid content, and 
therefore suitable for the alkaline transesterification.

The summarized results of the effect of the process variables on the biodiesel yield are presented in Figure 1. It is apparent from the Figure that increase in catalysts conscetration resulted in decrease in the yield followed by slight increase. On the other hand, increase in the methanol and temperature resulted only in slight increase in the yields. A much pronouced increase in yield of the biodiesel was observed with increase in reaction time (Figure 1).

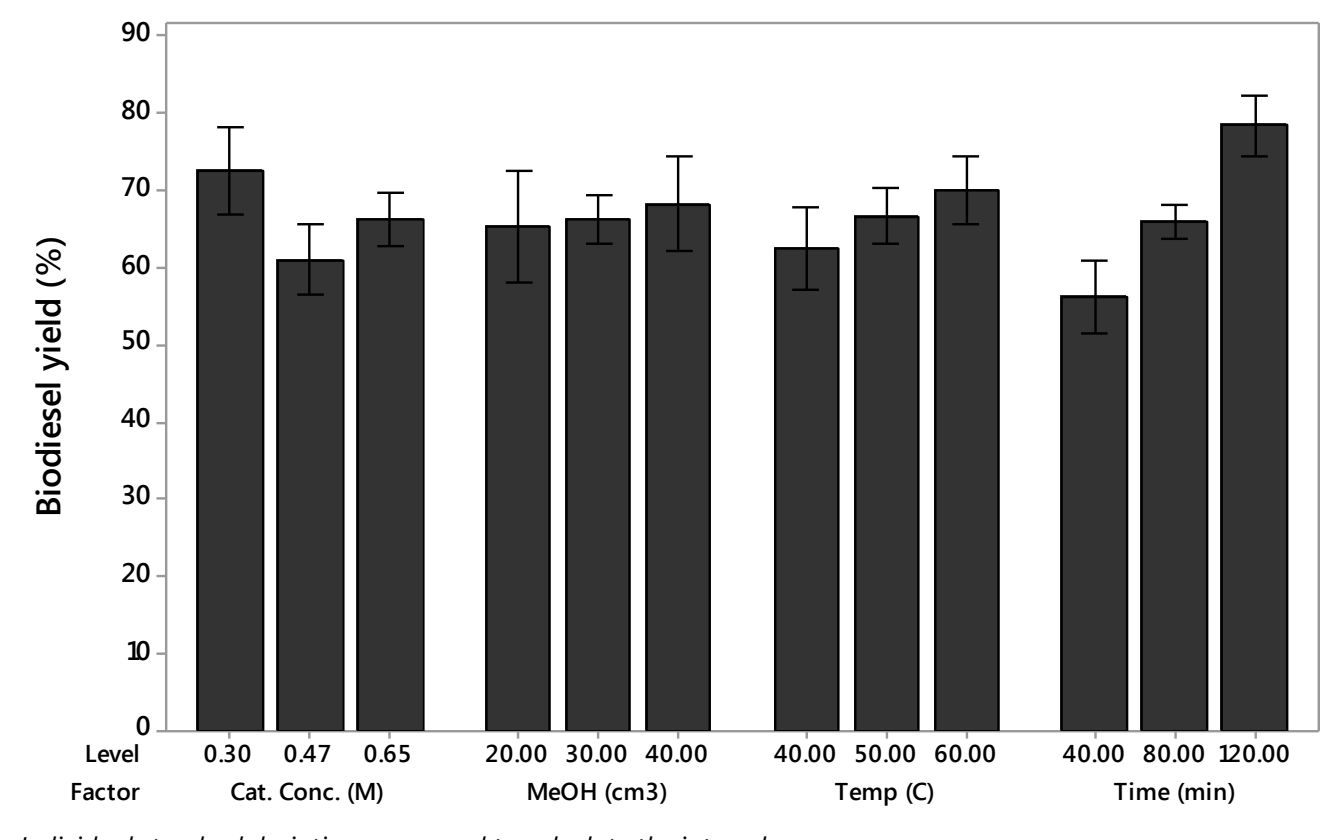

Individual standard deviations were used to calculate the intervals.

Figure 1: Mean biodiesel yield against levels of the process variables investigated

\section{Process Model Development}

Results of Analysis of variance are presented in Table 3. The results reveal that the linear, interaction $(2 \mathrm{FI})$ and quadratic terms are significant $(p<0.05)$ while cubic terms are not significant $(p>0.05)$.

Table 4 further shows that with the exception of catalyst concentration (c), all the individual effects are significant $(p<0.05)$, and six of the ten interaction terms are also significant ( $p$ $<0.05$ ). It is noteworthy that all the four interaction terms involving temperature $(d)$ are statistically not significant $(p<0.05)$.

The coefficient of determination $\left(R^{2}\right)$ shows that the model, including all the linear and quadratic terms, account for about $96 \%$ of the experimental results obtained $\left(R^{2}=0.9605\right)$ with quite good prediction ability (Pred $R^{2}=0.9106$ ). On eliminating the terms that are not statistically significant from the model, the final equation (Eq. 5) based on coded terms was obtained.

$$
\begin{gathered}
\text { Yield }=61.27+3.76 d+10.71 t-1.3 m-6.55 c+9.985 t^{2}-2.08 c^{2}-6.50 d t-1.50 t m \\
-2.93 t c+17.39 m c
\end{gathered}
$$


Table 3. Sequential Model Sum of Squares for $L$. lanceolata

\begin{tabular}{llllll}
\hline Source & Sum of square & DF & Mean Square & F Value & Prob > F \\
\hline Mean & & & & & \\
Linear & $2.561 \mathrm{E}+005$ & 1 & $2.561 \mathrm{E}+005$ & & \\
2FI & 4593.19 & 5 & 918.64 & 75.21 & $<.0001$ \\
Quadratic & $\frac{428.61}{27.91}$ & $\underline{10}$ & $\underline{42.86}$ & $\underline{8.72}$ & $\underline{1.0001}$ \\
Cubic & 118.00 & 18 & 6.56 & 2.16 & 0.02262 \\
Residual & 60.64 & 20 & 3.03 & & \\
Otal & & & & & \\
\hline
\end{tabular}

Table 4. Analysis of Variance for Response Surface Model for Lophira lanceolata

\begin{tabular}{llllll}
\hline Source & Sum of Square & DF & Mean Square & F-Value & Prob $>$ F \\
\hline Model & 5021.80 & 15 & 334.79 & 68.08 & $<0.0001$ \\
Temp. $(d)$ & 316.48 & 1 & 316.48 & 64.35 & $<0.0001$ \\
Time $(t)$ & 1593.01 & 1 & 1593.01 & 323.93 & $<0.0001$ \\
Methanol $(m)$ & 383.35 & 1 & 383.35 & 77.95 & $<0.0001$ \\
Cat. Conc. $(c)$ & 19.44 & 1 & 19.44 & 3.95 & 0.0534 \\
Batch $(e)$ & 180.40 & 1 & 180.40 & 36.68 & $<0.0001$ \\
$d t$ & 0.000 & 1 & 0.000 & 0.000 & 1.0000 \\
$d m$ & 1.13 & 1 & 1.13 & 0.23 & 0.6349 \\
$d c$ & 2.09 & 1 & 2.09 & 0.43 & 0.5175 \\
$d e$ & 15.04 & 1 & 15.04 & 3.06 & 0.0876 \\
$t m$ & 98.00 & 1 & 98.00 & 19.93 & $<0.0001$ \\
$t c$ & 138.33 & 1 & 138.33 & 28.13 & $<0.0001$ \\
$t e$ & 54.00 & 1 & 54.00 & 10.98 & 0.0019 \\
$m c$ & 60.95 & 1 & 60.95 & 12.39 & 0.0011 \\
me & 37.50 & 1 & 37.50 & 7.63 & 0.0085 \\
$c e$ & 21.57 & 1 & 21.57 & 4.39 & 0.0423 \\
Residual & 206.55 & 42 & 4.92 & & \\
Lack of Fit & 206.55 & 34 & 6.07 & & \\
Pure Error & 0.000 & 8 & 0.000 & & \\
Cor Total & 5228.34 & 57 & & & \\
\hline
\end{tabular}

Effect of the Process Variables of the Biodiesel Yield

Figure 2 to 4 present the contour plots showing effect of various process variables on the conversion of $L$. lanceolata oil into biodiesel as captured by the model (Eq.3). Each plot presents the effect of two variables on the biodiesel yield while holding the other variables at constant level.

Figure 2 shows the interaction between amount of methanol and reaction temperature. Biodiesel yield increases with increase in volume of methanol and reaction temperature while holding reaction time and catalyst concentration at constant levels of 80 minutes and $0.88 \mathrm{M}$, respectively. Evidently, at any given temperature, biodiesel yield can be increased by increasing the amount of methanol, and vice versa. High yields $(>64 \%)$ are only obtained when $>35 \mathrm{~cm}^{3}$ of methanol was used when the reaction temperature is above $48^{\circ} \mathrm{C}$ (Figure 1).This is in agreement with Meher et al. (2006) who observed from a survey of literature that for complete transesterification of the oils to be achieved an excess of alcohol is required to drive the reversible reaction to the right for greater conversion in a reasonable time.

Figure 3 shows the contour plot of reaction time against reaction temperature at constant catalyst concentration $(0.65 \mathrm{M})$ and amount of methanol $\left(30 \mathrm{~cm}^{3}\right)$. The plot shows that increase in reaction time and temperature results in 
increase in biodiesel yield although the conversion tends to more sensitive to change in reaction time. At any given temperature, the biodiesel yield can be increased to up to over $70 \%$ by increasing the reaction time. It is however possible to achieve yields of 64 to $70 \%$ with reaction time of less than 70 minutes when the reaction temperature is between 55 to $60^{\circ} \mathrm{C}$. Nevertheless, yields above $70 \%$ can only be achieved with reaction time of $>105$ minutes, irrespective of the reaction temperature.
Figure 4 is a contour plot showing the effect of catalyst concentration and reaction temperature on biodiesel yield at a constant reaction time (120 minutes) and amount of methanol (25. $\left.41 \mathrm{~cm}^{3}\right)$. At catalyst concentration of $0.30 \mathrm{M}$ the biodiesel yield was $81.4 \%$ at $40^{\circ} \mathrm{C}$, but highest yield of biodiesel was obtained at temperature of $55^{\circ} \mathrm{C}$ and catalyst concentration of above $0.30 \mathrm{M}$ with $88.1 \%$ biodiesel yield.

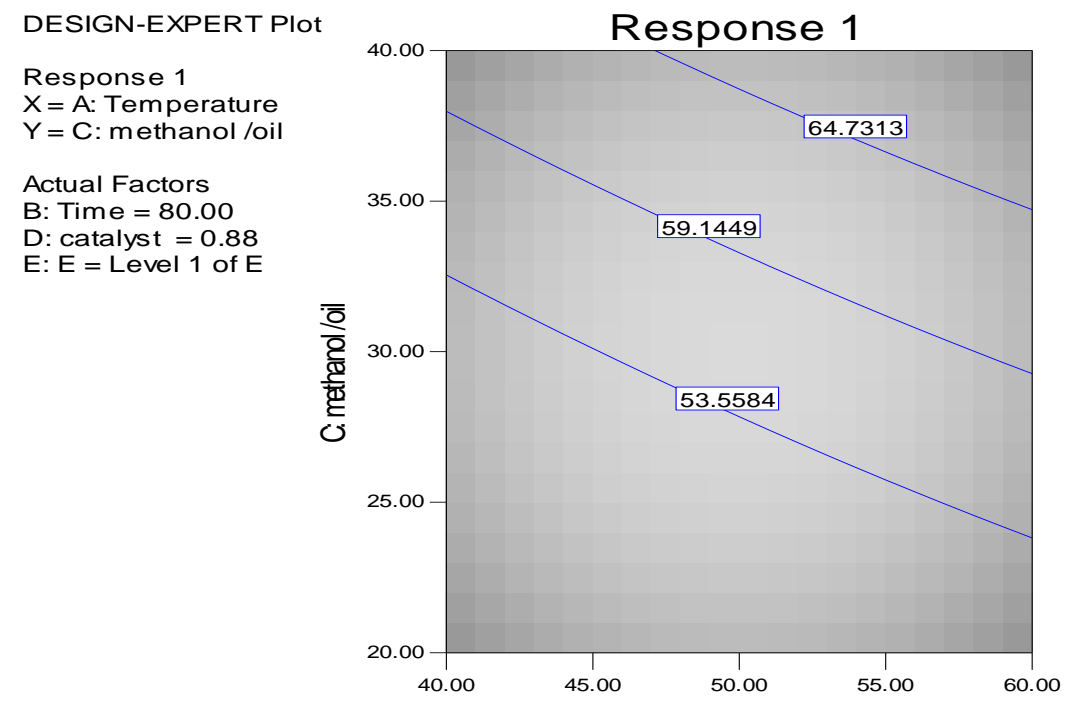

A: Temperature

Figure 2: Plot of amount of methanol against reaction temperature for conversion of $L$. lanceolate into biodiesel.

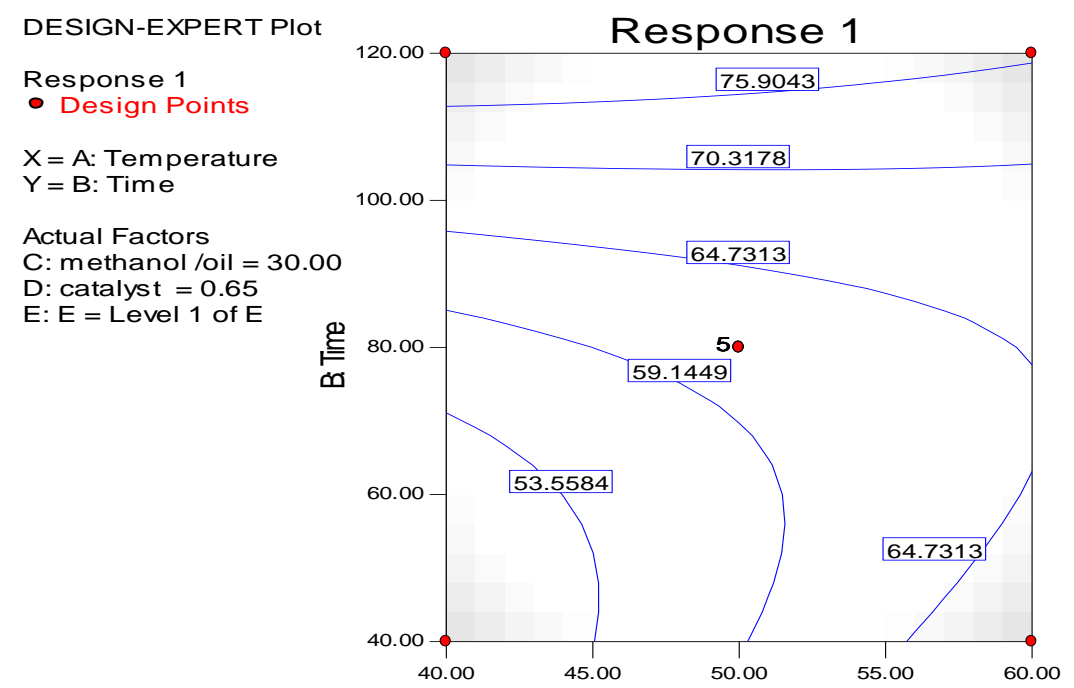

A: Temperature

Figure 3: Contour plot of reaction time versus reaction temperature for conversion of $L$. lanceolate into biodiesel. 
This suggests that increased in catalyst concentration decreases the conversion rate, but favoured biodiesel yields when temperature increased from 40 to $60^{\circ} \mathrm{C}$. In general, high yields can be achieved at longer reaction time irrespective of reaction temperature. It appears that temperature has no major effect on the conversion of vegetable oil into biodiesel as observed by Qian et al. (2008).
Figure 4 shows the contour plot of catalyst concentration against reaction temperature at a constant reaction time (120 $\mathrm{min}$ ) and amount of methanol $\left(25.41 \mathrm{~cm}^{3}\right)$. The figure shows that increase in catalyst concentration appear to decrease the biodiesel yield. Reaction temperature, on the other hand, seems to have little effect on the yield. Highest yields of biodiesel $(>75 \%)$ can be obtained with catalysts concentration below $0.65 \mathrm{M}$ when the reaction temperature is below $59^{\circ} \mathrm{C}$.

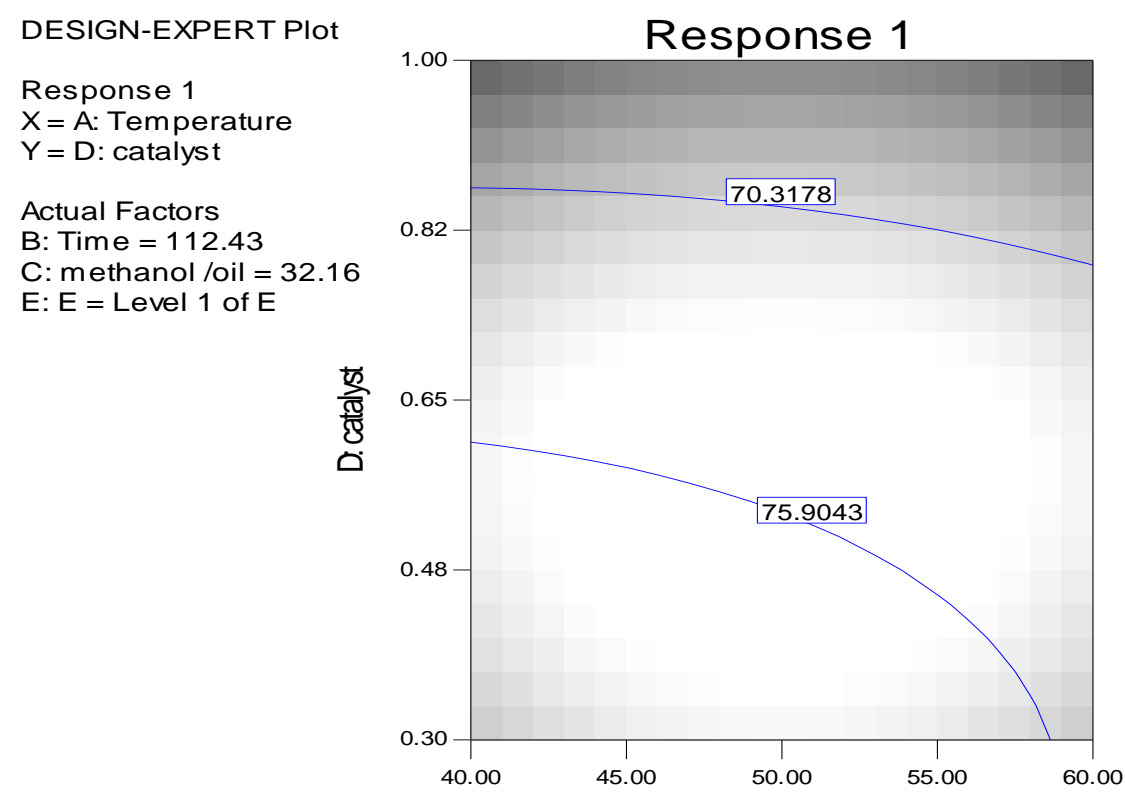

A: Temperature

Figure 4: Plot of catalyst concentration versus reaction temperature for conversion of $L$. lanceolate into biodiesel.

\section{Molecular composition of the biodiesel} $\mathrm{GC} / \mathrm{MS}$ results reveal that the biodiesel from the transesterification of $L$. lanceolata oil consists predominantly of methyl ester of octadecenoic acid $(>69 \%)$. In general, all the fatty acids methyl ester are either saturated or monounsaturated; with no detectable di-, tri- and polyunsaturated fatty acids. This is a desirable property with respect to the stability of the biodiesel as biodiesels with high degree of unsaturation have been linked to low stability index (Knothe and Dunn, 2003). However, such low levels of unsaturation and relatively high proportion of long chain compounds could also have a negative effect on cold finger plugging point (Ramos et al., 2009)and might therefore be responsible for the high levels of cloud and pour points of the biodiesel. 


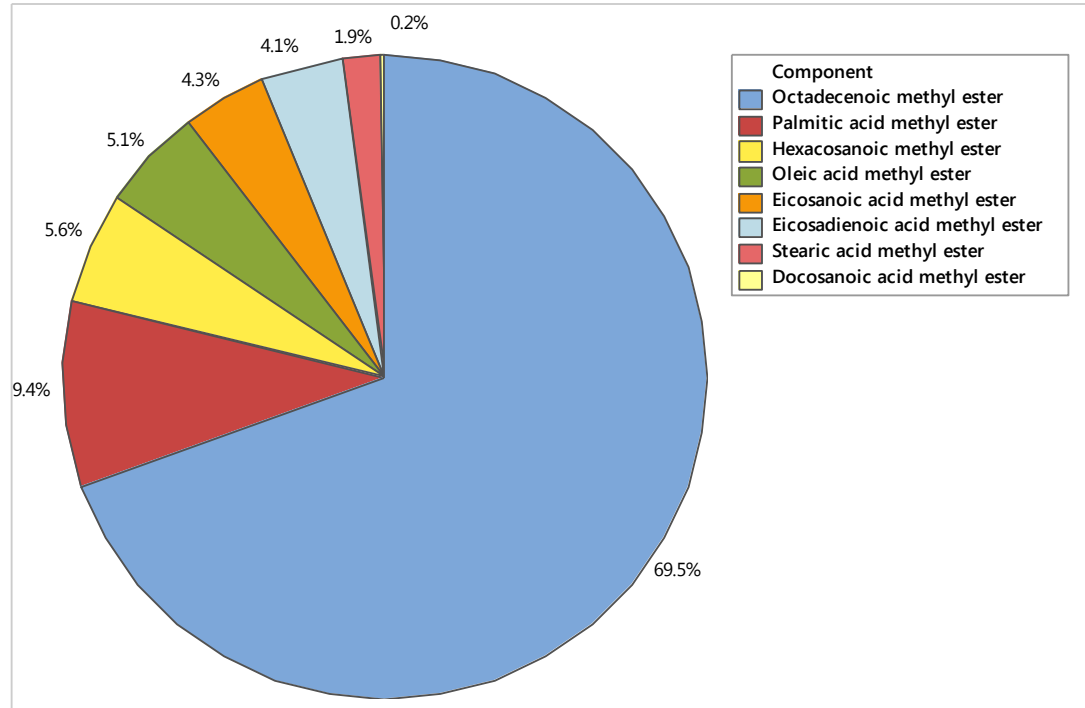

Figure 5: Composition of the biodiesel obtained from the transesterification of $L$. lanceolata seed oil.

Table 5 shows the fuel properties of the biodiesel prepared from the $L$. lanceolata seed oil alongside ASTM D6751 standards for comparison. Notably, the biodiesel has high cetane number compared to biodiesels from many other sources (Bajpai and Tyagi, 2006; Ramos et al., 2009) despite its low degree of unsaturation with which it has been observed to correlate positively (Knothe et al., 2003; Ramos et al., 2009). The relatively high cetane number of the biodiesel may however be due to the significant proportion of methyl ester of the $\mathrm{C}_{20+}$ long chain fatty acid acids(Ramos et al., 2009). Surprisingly, the biodiesel has quite low viscosity $\left(2.70 \mathrm{~mm}^{2} / \mathrm{s}\right.$, @ $\left.40^{\circ} \mathrm{C}\right)$, similar to Linseed oil biodiesel (Refaat, 2011), despite its high proportion $(69.5 \%)$ of methyl oleate with viscosity of $4.51 \mathrm{~mm}^{2} / \mathrm{s}$ at $40^{\circ} \mathrm{C}$ (Knothe and Steidley, 2005) coupled with significant amounts of high molecular weight saturated fatty acids methyl ester (Refaat, 2009).Nevertheless, the low viscosity, coupled with relatively low density, is good for atomization in the combustion and could thus reduce formation of soot and engine deposits as may otherwise be suggested by the high ash content of the biodiesel. The relatively high flash point $\left(150^{\circ} \mathrm{C}\right)$ reduces risks of fire. The cloud point and pour point are quite high and compares only to tallow and palm biodiesels (Dunn, 2005), which might be a consequence of the high proportion of long chain and saturated fatty acids methyl esters in the biodiesel (Refaat, 2009; Rodrigues et al., 2006). Although most of the parameters are within the requirements for good biodiesel, ash content and sulphur content are significantly above the minimum requirements.

Table 5: Fuel properties of the biodiesel obtained from L. lanceolata seed oil.

\begin{tabular}{llll}
\hline Parameter & Biodiesel & ASTM D6751 & EN 14214 \\
\hline Biodiesel content (\%) & $96.00 \pm 5.50$ & - & $96.5 \min$ \\
Acid value $(\mathrm{mgKOH} / \mathrm{g})$ & $0.53 \pm 0.01$ & $0.5 \max$ & $0.5 \max$ \\
Density $\left(\mathrm{g} / \mathrm{cm}^{3}\right)$ & $0.81 \pm 0.03$ & - & $0.86-0.90$ \\
Viscosity $\left(\mathrm{mm}^{2} / \mathrm{s}, @ 40^{\circ} \mathrm{C}\right)$ & $2.70 \pm 0.12$ & $1.9-6.0$ & $2.0-5.0$ \\
Free glycerol (wt. \%) & $0.023 \pm 0.001$ & $0.02 \max$ & 0.02 max \\
Total glycerol (wt.\%) & $0.09 \pm 0.001$ & $0.25 \max$ & $0.25 \max$
\end{tabular}




\section{Table 5 Continued}

Cetane number
Flash point $\left({ }^{\circ} \mathrm{C}\right)$
High heating value $(\mathrm{MJ} / \mathrm{kg})$
Pour point $\left({ }^{\circ} \mathrm{C}\right)$
Cloud Point $\left({ }^{\circ} \mathrm{C}\right)$
Ash $(\%)$
Sulphur $($ wt. \%)

$76.74 \pm 0.01$
$150.00 \pm 5.01$
$50.99 \pm 0.50$
$6.0 \pm 1.10$
$18 \pm 1.21$

$\begin{array}{ll}47 \mathrm{~min} & 51 \mathrm{~min} \\ 100 \mathrm{~min} & 100 \mathrm{~min} \\ - & - \\ - & - \\ \text { Report } & -\end{array}$

$0.042 \pm 0.001$

$0.02 \max$

$0.02 \max$

$0.0404 \pm 0.00$

10 ppm max

10 ppm max

\section{CONCLUSION}

The experament results showed that optimal yield $(85 \%)$ of biodiesel is obtained when transesterification of $L$. Lanceolataseed oil is conducted at at reaction temperature of $50^{\circ} \mathrm{C}$, and reaction time of 120 minutes when $30 \mathrm{~cm}^{3}$ (per $5 \mathrm{~g}$ of oil) of $0.30 \mathrm{M}$ methanolic sodium hydroxide was used $30 \mathrm{~cm}^{3}$. The biodiesel so obtained was found to consist dominantely of octadecanoic acid methyl ester, and was observed be very fluid with most of it fuel properties in conformity with ASTM standards making it suitable as fuel for diesel engines.

\section{REFERENCES}

Abbaszaadeh, A., Ghobadian, B., Omidkhah, M.R. and Najafi, G. (2012) Current biodiesel production technologies: A comparative review. Energy Conversion and Management, 63: 138-148.

Antolin, G., Tinaut, F.V., Briceno, Y., Castano, V., Pirez, C. and Ramirez, A.I. (2002) Calcium oxide as a solid base catalyst for transesterification of soybean oil. Bioresource Technology, 83: 111 - 114.

Atadashi, I.M., Aroua, M.K. and Aziz, A.A. (2010) High quality biodiesel and its diesel engine application: A review. Renewable and Sustainable Energy Reviews, 14: 1999-2008.

Bajpai, D. and Tyagi, V.K. (2006) Biodiesel: Source, Production, Composition, Properties and its Benefits. Journal of Oleo Science, 55: 487-502.

Demirbas, A. (2003) A Biodiesel Fuels from Vegetable Oils via Catalytic and Noncatalyst Supercritical Alcohol
Transesterification and other Method: a survey. Energy Conversion Management, 44(13): 2093-2109.

Demirbas, A. (2008) Relationships derived from physical properties of vegetable oil and biodiesel fuels. Fuel, 87: 1743-1748.

Dunn, R.O. (2005) Cold Weather Properties and Performance of Biodiesel., in: Knothe, G., van Gerpen, J., Krahl, J. (Eds.), The Biodiesel Handbook. AOCS Press, Champaign, IL, p. 501.

Enweremadu, C.C. and Mbarawa, M.M. (2009) Technical aspects of production and analysis of biodiesel from used cooking oil-A review. Renewable and Sustainable Energy Reviews, 13: 22052224.

Fan, X., Wang, X. and Cheng, F. (2010) Two Novel Approaches Used to Produce Biofuel from Low-cost Feedstock. The Open Fuels and Energy Science Journal, 3: $23-27$.

Fan, X., Wang, X. and Cheng, F. (2011) Biodiesel Production from Crude Cotton seed Oil: An optimization Process Using Response surface Methodology. The Open Fuels and Energy Science Journal, 4: 1-8.

Gondra, Z.A. (2010) Study of factors influencing the quality and yield of biodiesel produced by transesterification of vegetable oils, Faculty of Engineering and Sustainable Development. University of Gavle, p. 112.

Gui, M.M., Lee, K.T. and Bhatia, S. (2008) Feasibility of edible oil vs. non-edible oil 
vs. waste edible oil as biodiesel feedstock. Energy, 33: 1646-1653.

Haas, M.J. (2005) Improving the economics of biodiesel production through the use of low value lipids as feedstocks: vegetable oil soapstock. Fuel Process Technol, 86, 1087-1096.

Issariyakul, T., Kulkarni, M.G., Meher, L.C., A.K., D. and N.N., B. (2008) Heterogeneous catalysts for biodiesel production. Chemical Engineering Journal, 140: 77-85.

Karmakar, A., Karmakar, S. and Mukherjee, S. (2010) Properties of various plants and animals feedstocks for biodiesel production. Bioresource Technology, 101, 7201-7210.

Knothe, G. and Dunn, R.O. (2003) Dependence of oil stability index of fatty compounds on their structure and concentration and presence of metals. Journal of the American Oil Chemists' Society, 80: 1021-1026.

Knothe, G., Matheaus, A.C. and Ryan, T.W. (2003) Cetane numbers of branched and straight-chain fatty esters determined in an ignition quality tester ${ }^{3}$. Fuel, 82: 971975.

Knothe, G. and Steidley, K.R. (2005) Kinematic viscosity of biodiesel fuel components and related compounds: Influence of compound structure and comparison to petrodiesel fuel components. Fuel, 84: 1059-1065.

Koh, M.Y. and Ghazi, T.I.M. (2011) A review of biodiesel production fromJatropha curcas L. oil. Renewable and Sustainable Energy Reviews, 15: 2240-2251.

Krisnangkura, K.A. (1986) Simple method for estimation of cetane index of vegetable oil methyl esters. Journal of the American Oil Chemists' Society, 63: 552-553.

Leung, D.Y.C. and Guo, Y. (2006) Transesterification of neat and used frying oil: optimization for biodiesel production. Fuel Process Technol, 87: 883-890.

Meher, L.C., Vidya Sagar, D. and Naik, S.N. (2006) Technical aspects of biodiesel production by transesterification-a review. Renewable and Sustainable Energy Reviews, 10: 248-268.

Meneghetti, S.M.P., Meneghetti, M.R., Serra, T.M., Barbosa, D.C. and Wolf, C.R. (2007) Biodiesel Production from Vegetable Oil Mixtures: Cottonseed, Soybean, and Castor Oils. Energy Fuels, 21: $3746-3747$.

Moser, B.R. (2008) Influence of Blending Canola, Palm, Soybean, and Sunflower Oil Methyl Esters on Fuel Properties of Biodiesel. Energy \& Fuels, 22: 43014306.

Muhammad, A.B., Bello, K., Tambuwal, A.D. and Aliero, A.A. (2015) Assessment and Optimization of Conversion of L. siceraria Seed Oil into Biodiesel using $\mathrm{CaO}$ on Kaolin as Heterogeneous Catalyst. International Journal of Chemical Technology, 7: 1 - 11.

Muhammad, A.B., Obianke, M., Gusau, L.H. and Aliero, A.A. (2016) Optimization of process variables in acid catalysed in situ transesterification of Hevea brasiliensis (rubber tree) seed oil into biodiesel. Biofuels, 8(5) 1-10.

Nkafamiya, I.I., Maina, H.M., Osemeahon, S.A. and Modibbo, U.U. (2010) Percentage oil yield and physiochemical properties of different groundnut species (Arachis hypogaea). African Journal of Food Science, 4: 418 - 421.

Prommuak, C., Pavasant, P., Quitain, A.T., Goto, M. and Shotipruk, A. (2012) Microalgal lipid extraction and evaluation of single-step biodiesel production. Engineering Journal, 16: 157-166.

Qian, J.F., Wang, F., Liu, S., and Yun (2008) In situ alkaline transesterification of cottonseed oil for production of biodiesel and nontoxic cottonseed. Bioresource Technology, 99(18):9009-9012

Ramos, M.J., Fernández, C.M., Casas, A., Rodríguez, L. and Pérez, Á. (2009) Influence of fatty acid composition of raw materials on biodiesel properties. Bioresource Technology, 100: 261-268.

Refaat, A.A. (2009) Correlation between the chemical structure of biodiesel and its physical properties. International Journal 
of Environmental Science \& Technology, 6: 677-694.

Refaat, A.A. (2011) Biodiesel production using solid metal oxide catalysts. International Journal of Environmental Science \& Technology, 8: 203-221.

Rodrigues, J.d.A., Cardoso, F.d.P., Lachter, E.R., Estevão, L.R.M., Lima, E. and Nascimento, R.S.V. (2006) Correlating chemical structure and physical properties of vegetable oil esters. Journal of the American Oil Chemists' Society, 83: 353-357.

Silva, G.F., Camargo, F.L. and Ferreira, A.L. (2011) Application of response surface methodology for optimization of biodiesel production by transesterification of soybean oil with ethanol. Fuel Processing Technology, 92: 407-413.

Singh, S.P. and Singh, D. (2009) Biodiesel production through the use of different sources and characterization of oils and their esters as the substitute of diesel: a review. Renewable and Sustainable Energy Reviews, 14: 200-216.

Wiebe, K., Croppenstedt, A., Raney, T., Skoet, J. and Zurek, M. (2008) The state of food and agriculture: biofuels-prospects risks and opportunities. Food and Agriculture Organization of the United Nations Rome.

Yang, C.-Y., Fang, Z., Li, B. and Long, Y.-f. (2012) Review and prospects of Jatropha biodiesel industry in China. Renewable and Sustainable Energy Reviews, 16: 2178-2190. 